Tropical Journal of Pharmaceutical Research August 2010; 9 (4): 373-377

(C) Pharmacotherapy Group, Faculty of Pharmacy, University of Benin,

Benin City, 300001 Nigeria.

All rights reserved.

Research Article

Available online at http://www.tjpr.org

\title{
Production of Antibiotics from Soil-Isolated Actinomycetes and Evaluation of their Antimicrobial Activities
}

\author{
Basavaraj K Nanjwade ${ }^{1 \star}$, S Chandrashekhara ${ }^{2}$, Prakash S \\ Goudanavar $^{2}$, Ali M Shamarez ${ }^{1}$ and Fakirappa V Manvi ${ }^{1}$ \\ ${ }^{1}$ KLES's College of Pharmaceutical Sciences, K.L.E. University, Nehru Nagar, Belgaum, \\ ${ }^{2}$ KLES's College of Pharmaceutical Sciences, Nipani, Karnataka, India.
}

\begin{abstract}
Purpose: To investigate the production of antibiotic from actinomycetes isolated from soil and evaluate its antimicrobial activities.

Methods: In a medium formulation study, A-4 and A-4 actinomycete mutant strains (out of the six strains selected from the nine actinomycetes that were screened) were evaluated for maximum antibiotic production using various carbon and nitrogen sources. Zone of inhibition and packed cell volume were the parameters used for the evaluation. Various fermentation conditions such as $\mathrm{pH}$, temperature and dissolved oxygen were also optimized for maximal production of antibiotic from both A4 and $A-4$ mutant.

Results: Some actinomycetes strains showed promising antimicrobial activity against different strains of bacteria and fungi. Out of the six strains selected, one strain, designated A-4, showed maximum antimicrobial property against Gram positive and Gram negative strains as well as against various fungi. Conclusion: Findings from this investigation reveal that strain A-4 and A-4 mutant strains, in that order, exhibited superior antimicrobial activities to other soil isolates of actinomycetes.
\end{abstract}

Keywords: Actinomycete, Antibiotic, MIC, fermentation. 


\section{INTRODUCTION}

The continuing success of a biotechnologist in the search for microbial metabolites for use as antimicrobial compounds (antibiotics) is critical to combating human, animal and plant diseases. Microorganisms constitute an inexhaustible reservoir of compounds with pharmacological, physiological, medical or agricultural applications [1-3]. Antibiotics continue to play a crucial role in the development of tissue culture techniques and basic screenings, primarily in biochemistry, molecular biology, microbiology and genetics (including genetic engineering) and to a lesser extent, pharmacology and organic chemistry.

The actinomycetes are Gram positive, organisms that tend to grow slowly as branching filaments. Many actinomycetes will grow on the common bacteriological media used in the laboratory, such as nutrient agar, trypticase soy agar, blood agar, and even brain-heart infusion agar. Actinomycetes encompass a wide range of bacteria. They have universal occurrence and play an active part in the cycle of nature $[4,5]$. Antibiotics are the best known products of actinomycete. The morphology of an actinomycete growing on agar can provide useful and rapid clues to its identity, but viewing isolated colonies can give little worthwhile information. Morphological characters are still widely used for characterizing genera, for example, the presence or absence of spores on the substrate mycelium or the formation of zoospores in specialized spore vesicles or sporangia. The ability to produce motile spores is more widespread in the actinomycetes. [6].

The present study is an attempt to produce antibiotics from actinomycetes, isolated from soil, by fermentation and the determination of their antimicrobial activity.

\section{EXPERIMENTAL Materials}

Dextrose IP, $\mathrm{NaCl}$, soyabean meal, nbutanol, silicon oil, dimethyl sulphoxide (DMSO), n-hexane, tryptone, lactose, maltose, fructose, yeast extract powder, nutrient agar, agar powder, International Streptomycetes Project (ISP) 2 to 7 media, actinomycetes agar, Bennett's agar, nutrient broth, sucrose, silica gel 60-120 mesh, silicagel powder, chloroform, ethyl acetate, and starch were obtained from Nice Chemicals Ltd, Mumbai. Magnesium sulphate, potassium dihydrogen phosphate, methanol, silica gel (TLC grade), peptone (Loba Chemicals Ltd, Mumbai), skimmed milk and glucose were also used in this study. They were all of analytical/pharmacopoeial grade and used as received without further purification.

\section{Optimization of fermentation parameters}

The following fermentation parameters were found to be ideal for maximum antibiotic productivity using A-4 strain of actinomycete [10]: (a) temperature, $28{ }^{\circ} \mathrm{C}$; (b) $\mathrm{pH}, 7.0$ (c); dissolved oxygen $\left(\mathrm{DO}_{2}\right)$ concentration, $60 \%$; (d) harvesting time (fermentation duration), $96 \mathrm{~h}$; and (e) inoculum concentration, 10 $\%$ v/v.

\section{Optimization of fermentation duration}

The duration of the fermentation process was optimized to obtain the harvesting time for maximum antibiotic productivity. Using the foregoing media formulation and fermentation parameters and conditions, the media were prepared and sterilized, inoculated with $10 \%$ of a 24-h incubated inoculum of A-4 and then incubated for 0 to $144 \mathrm{~h}$. The harvesting time for maximum antibiotic productivity was determined by packed cell volume (PCV) and antimicrobial activity using cup-plate method [10]. 


\section{Downstream process for fermentation}

Fermentation was carried out for 4 days at the optimized fermentation parameters indicated above. Following fermentation, the medium was centrifuged at $10,000 \mathrm{rpm}$ for half an hour at $4{ }^{\circ} \mathrm{C}$ to remove biomass and cell debris and the supernatant was separated. The cell pellet of the biomass was triturated with sterile sand to disrupt the cell wall, washed with Tris buffer $(\mathrm{pH}$ 7.4) filtered and centrifuged, and the supernatant, which contained all the intracellular components, was separated out. Both sets of supernatant were assessed for antimicrobial activity [12].

\section{Determination of antimicrobial activity}

Antimicrobial activity was determined by cup plate technique. The test bacteria were grown on nutrient agar while the test fungi were grown on Sabouraud dextrose agar. The extracts, i.e., supernatant liquid from fermentation media, were dissolved in $200 \mathrm{ml}$ of ethyl acetate and $50 \mu \mathrm{L}$ of the solution was placed in the agar cup. Growth inhibition was measured after incubation for $24 \mathrm{~h}$ at $37{ }^{\circ} \mathrm{C}$ for bacteria and $72 \mathrm{~h}$ at $27{ }^{\circ} \mathrm{C}$ for fungi. Antimicrobial activity was estimated by measuring the inhibition zone diameters [11,12].

\section{Structural identification of antimicrobial compound}

The structure of the isolated compound was characterized using nuclear magnetic resonance (NMR) spectroscopy [13].

\section{RESULTS}

\section{Fermentation process}

The optimization data for optimum growth and antibiotic production with regard to the maximum duration of fermentation are shown in Table 1.
Table 1: Optimization data for duration of fermentation for antibiotic production

\begin{tabular}{ccccc}
\hline $\begin{array}{c}\text { Time } \\
\text { (h) }\end{array}$ & \multicolumn{2}{c}{ A-4 } & \multicolumn{2}{c}{ A-4 mutant } \\
\cline { 2 - 5 } & $\begin{array}{c}\text { PCV } \\
\text { (\%) }\end{array}$ & $\begin{array}{c}\text { Zone of } \\
\text { inhibition } \\
\text { (cm) }\end{array}$ & $\begin{array}{c}\text { PCV } \\
\text { (\%) }\end{array}$ & $\begin{array}{c}\text { Zone of } \\
\text { inhibition } \\
\text { (cm) }\end{array}$ \\
\hline 0 & -- & -- & -- & -- \\
12 & 0.1 & -- & 0.02 & -- \\
24 & 0.2 & 2.0 & 0.1 & -- \\
36 & 0.25 & 2.3 & 0.3 & 2.1 \\
48 & 0.4 & 2.2 & 0.4 & 2.4 \\
60 & 0.4 & 2.4 & 0.6 & 2.7 \\
72 & 0.7 & 2.5 & 0.9 & 2.8 \\
84 & 0.9 & 2.7 & 1.5 & 3.2 \\
96 & 1.5 & 2.7 & 3.3 & 3.6 \\
& & & &
\end{tabular}

Well diameter $=0.9 \mathrm{~cm}$; test organism $=$ Klebsiella pneumoniae; $P C V=$ packed cell volume

\section{Antimicrobial activity}

Table 2 shows the minimum inhibitory concentration (MIC) of the isolated antibiotics from A-4 and A-4 mutant fermentation broth. The antibiotics showed broad spectrum of activity against Gram-positive and Gramnegative organisms with $\mathrm{MIC}$ in the range of $100-125$ and $62.5-100 \mu \mathrm{g} / \mathrm{ml}$, for A-4 and A-4 mutant respectively. The isolated compounds also showed significant antifungal activity against fungal strains with MIC of 125 and $62.5-125 \mu \mathrm{g} / \mathrm{ml}$ for A-4 and A-4 mutant, respectively.

Table 2: MIC of the isolated antibiotics against bacteria and fungi

\begin{tabular}{lcc}
\hline Test microorganism & \multicolumn{2}{c}{ MIC $(\boldsymbol{\mu g} / \mathbf{m l})$} \\
& \multicolumn{2}{c}{$\begin{array}{c}\text { A-4 } \\
\text { mutant }\end{array}$} \\
\hline Gram-positive organisms & & \\
$\quad$ Staphylococcus aureus & 125 & 100 \\
$\quad$ Bacillus subtilis & 125 & 100 \\
Gram negative organisms & & \\
$\quad$ Escherichia coli & 125 & 100 \\
$\quad$ Pseudomonas aeruginosa & 100 & 62.5 \\
$\quad$ Klebsiella pneumoniae & 100 & 62.5 \\
Fungi & & \\
$\quad$ Candida albicans & 125 & 125 \\
$\quad$ Saccharomyces cerviciae & 125 & 62.5 \\
\hline
\end{tabular}




\section{Structure of antibiotic}

NMR spectroscopic data and the functional groups of the antibiotic are shown in Table 3.

Table 3: NMR spectroscopic data for the isolated antibiotic

\begin{tabular}{cl}
\hline $\boldsymbol{\delta}$ value & \multicolumn{1}{c}{ Functional group } \\
\hline 1.24 & Methyl H-shift \\
2.86 & Methyl H-shift \\
3.29 & Aldehyde \\
3.48 & Alcohols \\
3.7 & Esters \\
5.2 & Alkene \\
\hline
\end{tabular}

\section{DISCUSSION}

Medium formulation is necessary for each fermentation process. It is necessary to optimize each and every component of fermentation media by varying the concentration of media constituents in order to achieve maximum antibiotic production. The purpose of media optimization is to support efficient growth of microorganisms. Different combinations of medium constituents and sequences of optimized fermentation conditions need to be investigated to determine growth conditions that produce biomass that is physiologically best suited for antibiotic production.

For fermentation process optimization, a basal medium containing $0.3 \%$ yeast extract, $0.35 \% \mathrm{CaCO}_{3}$ and $0.5 \% \mathrm{NaCl}$ was used for antibiotic production as indicated in the literature $[10,12]$. In order to achieve maximum antibiotic production, experiments were conducted to optimize the various parameters such as carbon source, nitrogen source, temperature, $\mathrm{pH}, \mathrm{DO}_{2}$, and micronutrients etc. It was observed that rapid utilizable carbon source did not support the antibiotic production as antibiotic synthesis does not totally depend on the growth of the microorganism; rather, it depends upon the adverse conditions imposed by the medium or surroundings.
The antibiotics isolated from A-4 and A-4 mutant fermentation broth showed broad spectrum of activity against both Grampositive and Gram-negative organisms (MIC, $100-125 \mu \mathrm{g} / \mathrm{ml}$ ) a swell as antifungal activity (MIC, $62.5-125 \mu \mathrm{g} / \mathrm{ml}$ ). They demonstrated superior antimicrobial activity to other soil isolates of actinomycetes that were investigated. The A-4 mutant showed higher antibiotic potency. NMR studies showed that the antibiotic, A-4 strain, belongs to the macrolide group.

\section{CONCLUSION}

The findings from this investigation reveal that the strains, A-4 and A-4 mutant, which were soil isolates of actinomycetes, exhibited superior antimicrobial activity to other soil isolates of actinomycetes.

\section{REFERENCES}

1. Smith JE. Perspective in biotechnology and applied microbiology, Murray Moo-Young, 1989; pp 105-134.

2. Bulock J. Basic Biotechnology. Academic Press, 1987; pp 425-448.

3. Vandemme EJ. Biotechnology of Industrial Antibiotics. Dekker Series, Vol. 22, Marcel Dekker Inc., New York, 1948; pp 3-42.

4. Syker $G$ and Skinner FA. Actinomycetes: Characteristics and practical importance. Academic Press, London \& New York, 1973; pp 1-91 and 231-247.

5. Edward G. Bergey's J. Manual of Derminative Bacteriology. $9^{\text {th }}$ ed. WMC Brown Publishers, USA, 1974; pp 712-829.

6. Brun YV, Skimkets LJ. Prokaryotic development. ASM Press, 2000; pp 11-31.

7. Lebrihi A, Lamsaif D, Lefebure G, Germain P. Effect of ammonium ions on spiramycin biosynthesis in Streptomyces ambofaciens, Appl. Microbiol Biotechnol 1992; 37:382- 387.

8. Okada S, Iwamatu S. Scale-up production of milbemycin by Streptomyces hygroscopicus

subspecies aureolacrimosus with control of internal pressure, temperature. Aeration and Agitation, J Chem Technol Biotechnol 1997; 70: 179-187.

9. Jain PK, Jain PC. Production of heptaene antifungal antibiotic by Streptomyces purpeofuscus CM1261, Indian J Exp Biol. 2005; 43: 342-345.

10. James PDA, Edwards C, Dawson M. The effects of temperature, $\mathrm{pH}$ and growth rate on secondary metabolism in Streptomyces thermoviolaceus 


\section{Nanjwade et al}

grown in a chemostat. J Gen Microbiol 1991; 137: 1715-1720.

11. Haque SKF, Sen SK, Pal SC. Antimicrobial spectra and toxicity of antibiotics from Streptomyces antibioticus sr 15-4, Indian J. Microbiol 1996; 36: 113-114.
12. Antal N, Fiedler HP, Stackebrandt E, Beil W. Novel secondary metabolites from Micromonospora sp.Tii 6368. Taxonomy, fermentation, isolation and biological activities, J Antibiot 2005; 58(2): 95-102.

13. Gunther H. NMR Spectroscopy II edition, John Wiley and sons: New york 1986; 15-52. 